\title{
A Study on the Shaping and Training of Public Servant Leaders in
}

\section{Public Hospitals}

\author{
Jian Gong ${ }^{1}$, Jiang $\mathrm{Su}^{1}$, Jian Sun ${ }^{1}$, Fei $\mathrm{Ma}^{1}$, Xiaoming Dong ${ }^{2}$, Fanchen \\ Meng $^{3}$, Hongxia $\mathrm{Bi}^{1}$ (corresponding author) \\ ${ }^{1}$ Qiqihar Medical University, Qiqihar City, Heilongjiang Province, 161000, China \\ ${ }^{2}$ The Second Affiliated Hospital of Qiqihar Medical University, Qiqihar City, Heilongjiang \\ Province, 161000, China
}

${ }^{3}$ The Third Affiliated Hospital of Qiqihar Medical University, Qiqihar City, Heilongjiang Province, 161000, China

Keywords: Public hospital; Public servant leader; Connotation; Characteristics; Molding method

\begin{abstract}
In recent years, the theoretical research achievements in the management of academic circles in Europe and America and the practical management experience in the industry show that public servant leader plays a catalytic role in the healthy growth and harmonious development of enterprises. This paper firstly analyzed the value of public servant leaders to public hospitals, and then put forward the shaping method of public servant leaders in public hospitals. The results of this study can provide reference ideas for building a new leader image in public hospital.
\end{abstract}

\section{Introduction}

In recent years, European and American enterprise management academia and industry begin to pay attention to the leader's moral quality and social responsibility, and consider and explore the public servant leader, which emphasizes the leader's moral leadership. The head leadership behavior of each department in the public hospital has significant positive influence on employee's organizational identification and job involvement; public servant leaders can better provide scientific management advice for hospitals and improve their work enthusiasm and concentration so that to realize the goal of the department and hospital and improve the efficiency and competitiveness of the hospital.

\section{The Value of Public Servant Leaders to Public Hospitals}

Train and retain excellent staff. Intellectual capital is the key factor that determines the competitive strength of enterprises in the era of knowledge economy. Only those who are good at finding, evaluating, hiring and retaining good employees can win competitive advantage. Excellent staff has excellent working ability and positive working attitude. Their fate will be influenced by personal factors and will be influenced to a great extent by the way of leadership. Public servant leaders are good at motivating their work potential and arousing their enthusiasm for work. They give employees the right of job autonomy, which enables them to actively select ways of working, control their work, and determine their progress. They strive to create a good personal development opportunities for employees, and fully mobilize the enthusiasm of employees. They serve the workers wholeheartedly, and influence employees by examples. With the development of public servant leaders, more and better employees will emerge from the hospital. 
Enhance team work consciousness. The efficiency of employee is influenced not only by their intelligence and skills, but also by the ability and behavior of other employees. Compared with the personal ability, the cooperation within the team will have a greater impact on the business efficiency. Public servant leaders attach great importance to train team spirit. They actively participate in team building, give team decision-making power, and enhance team self-management ability; they encourage and support the construction of the staff community, pay attention to community members in terms of understanding, respecting and loving each other, so as to create a team atmosphere, and enhance corporate cohesion.

Enhance corporate reputation. Good corporate reputation can cultivate loyal customers, attract good employees, attract investors and strengthen the competitive edge of enterprises. As an enterprise navigator, the leader's values, business ethics and social responsibility will directly affect the corporate social behavior and business behavior, thereby affecting the reputation of the enterprise. Public servant leaders have lofty moral qualities and selfless dedication; their values and behavior can be recognized and praised by employees, customers, partners and the general public. Their leading enterprises can also get a good market reputation and social evaluation, and enhance their social image.

\section{Shaping Method for Public Servant Leader in Public Hospitals}

In hospital level. First, we should cultivate the sense of service of the department head with the idea of "put people first". Scholars at home and abroad have shown that public servant leaders are closely related to leaders' own traits, such as values and cultural accomplishment. As a country with a strict hierarchy since ancient times, there is often a high power distance between Chinese leaders and employees, and public servant leader behavior is often neglected. This research confirmed that the public servant leader behavior can better enhance the employee's organizational recognition and employee's job involvement. Therefore, the hospital should advocate the concept of service-oriented leadership, train the leadership of listening, empathy, altruism and other service skills, train the public servant consciousness of the department head, and advocate the idea of "people first and patient as the center". The hospital should provide many managers with the opportunity to learn advanced management concepts and improve its traditional management style as much as possible. At the same time, the hospital should insist on more employee oriented flexible management.

The second is to set up the service-oriented hospital culture from top to bottom. Studies have shown that organizational culture and organizational climate influence leadership styles. Therefore, the service oriented organizational culture can drive the leader's practice service behavior more. Many studies have confirmed that service leader behavior can further enhance employee's sense of organization as an intermediary effect. Employees with a high sense of organizational commitment also have higher job involvement. In a service oriented hospital culture, leaders exist not only as managers, but as service providers. Therefore, setting up a service oriented hospital culture can not only promote managers to improve their own leadership style, but also enhance their emotional attribution to hospitals. Employees form an emotional link between the mind and the organization, and employees are more trusting of the organization. It can provide a good working atmosphere for the staff, and make them concentrate on their own work, improve their work efficiency, and show a harmonious organization atmosphere for everyone and for me.

The third is to cut the dress according to one's figure, which means that management measures are formulated for different departments. For employees with heavy medical care and clinical care, it is necessary for the administrative departments to provide service-oriented leadership behavior. Managers should set up targeted management policies according to the 
nature and tasks of each department. Clinicians and nursing staff have direct contact with diagnosis and treatment and patients and have higher professional knowledge and skills with greater job stress. Therefore, the leaders of these departments have high professional authority, and should also be good at communicating with subordinates to find out the negative emotions in their work. For inexperienced young doctor, heads of department should make emotional counseling and teaching to help them summarize the experience and lessons; as for the nursing staff who often have irregular routines because of their need for work, the heads of the department should pay more attention to their health and life.

In the self level for department heads. First, respect and pay attention to the role of employees. The research confirms that the dimension of respect for employees under service leader has significant positive influence on the three dimensions of organizational identification, job involvement, dedication and concentration, which has the highest correlation. Therefore, the department heads in the daily work should be appreciated subordinates as an incentive, and listen to the advice of employees with attentions on communication in daily work communication. For young and inexperienced employees, we should encourage them often and help them build their confidence. Employees feel their own value is recognized, which can stimulate their work autonomy so that the employees have full mental state to focus on diagnosis and treatment work.

The second is concern about employees and depend on benefits of employee. In daily work, the person in charge of the Department is always oriented by work, and has a little concern for the staff. Department heads should be people-oriented, that is, to be good at finding the actual difficulties of employees, to ensure organizational interests at the same time to meet the needs of employees. For irregular clinical and nursing staff, the person in charge of the Department should pay attention to their physical health, and promptly dredge their unhealthy emotions. According to Maslow's hierarchy of needs theory, the head of the department meets the needs of the subordinates and provides opportunities for them to realize their professional ideals and self - fulfillment. Employees feel a sense of belonging to the hospital and they believe that the hospital can meet their interest needs and can influence their spontaneous engagement.

The third is equal with employees and equip with the ability of good communications. This study found that the approachable nature of service leaders has a greater impact on organizational identification and job involvement. Previous studies have shown that higher power distance leads to a gradual decline between leadership and subordinates. Equal footing with subordinates, approachable leaders are more loved by their employees. In daily work, the head of the department can not communicate with the staff as the leader's position, but will be able to win the hearts and minds of the people and get the trust of subordinates. If employees feel relaxed and harmonious in their work environment, they are also more active in their work and able to concentrate their efforts on serving patients.

The fourth is selfless dedication. The selfless dedication of service leader has the greatest relevance to employee's organizational identification and job involvement, and it can also influence the dedication of subordinates' work engagement. Fifth, the leadership should be upright in style and fair in dealing with subordinates. As a leader, the most important thing is to be fair and impartial to subordinates. Studies have shown that the Department responsible for the clean and honest can increase employees' organizational identification and job involvement. Leadership is not self dealing, abuse of power by the staff of the department responsible for the more recognized and respected. An impartial leader can stimulate employees' sense of justice and pride in their work, and work to prove themselves, without any selfish interests, and treat patients alike. 


\section{Summary}

The servant oriented leader is gradually being applied to the management practices of many profitable and non-profit organizations in Europe and America. Public servant leaders have the qualities of selfless devotion, and pay more attention to employees, partners, customers and the interests of society. With the traditional authoritarian or arbitrary leadership compared, servant leadership is conducive to the long-term development of the healthy growth of enterprises and employees. As the head of the department at the grassroots level, the person in charge of the department should pay attention to the role of employees, care for the welfare of employees, and work with employees on an equal footing. Leaders should set an example, and only in this way can we increase the staff's sense of organizational identity, improve work input, and provide higher quality medical services for patients with full mental state.

\section{References}

[1] Ju Xiaohong. The Influence of Servant Leadership on Employee's Job Performance[D]. Jiangxi Normal University, 2014.

[2] Wang Ping. Influence of Servant Leadership on Team Performance[D]. Jiangxi Normal University, 2014.

[3] Sun Jianmin, Wang Biying. Public Servant Leadership: Definition of Concept and Revision of Scale[J]. Business Economics and Management, 2010, (05): 24-30.

[4], Ling Qian, Wang Chunxiao, Zhang Xiujuan, Liu Xiaoping. The Influence of Servant Leadership, Service Atmosphere and Emotional Sense of Belonging Among Employees on Service Quality of Employees[J]. Travel Forum, 2010, (02): 199-207.

[5], Ling Qian, Wang Chunxiao, Zhang Xiujuan, Chen Weixin. Influence of Public Servant Leadership Style on Employee Service Quality[J]. Travel journal, 2010, (04): 68-75.

[6] Wang Biying. Public Servant Leadership: Revision and Effect of Scale[J]. Theoretical discussion, 2010, (02): 153-156. 